\title{
Impact of Inadequate Experience and Skill on the Construction Sector in KwaZulu-Natal, South Africa
}

\author{
Bonga Ntuli \\ Water Business Unit \\ Royal HaskoningDHV (Pty) Ltd \\ Pietermaritzburg, South Africa \\ bonga.ntuli@rhdhv.com
}

\author{
Dr Dhiren Allopi \\ Department of Civil Engineering \& Surveying \\ Durban University of Technology \\ Durban, South Africa \\ allopid@dut.ac.za
}

\begin{abstract}
Civil engineering contractors encounter serious challenges in order to sustain their businesses, especially in a weak economic climate. A certain level of construction experience, expertise and training are required to manage a sustainable construction company. The Construction Industry Development Board (CIDB) was established in 2000 as a statutory body to provide leadership to stakeholders and stimulate sustainable growth, reform and improvement of the construction sector for effective infrastructure delivery and improvement of construction skills. The objectives of this research were to investigate challenges faced by civil engineering contractors whilst making their enterprises sustainable. Contractors' views were presented at "Construction Indaba 2011" held on 1-2 June 2011 and hosted by eThekwini Municipality's Business Support, Tourism and Markets in Durban KwaZulu-Natal. Discussion and findings revealed to a skills' shortage in the construction section and underlined the need for continuous training of the contractors' employees. The South African government in conjunction with all stakeholders should develop and implement contractor programs to address the lack of technical and management skills in the construction sector.
\end{abstract}

Keywords: construction; development; training; survey; SEDA; CIDB; SMME; ssustainable construction firms

\section{INTRODUCTION}

A sustainable construction industry is critical to the economy of South Africa. In 1999 the construction industry contributed approximately $35 \%$ of the total gross domestic fixed investment and employed 230,000 employees [1]. The South African public sector expenditures regarding infrastructure works is the main contributor to the growth of the construction sector [2]. As a result, the South African government has identified that to achieve overall economic benefit, the development of construction enterprises needs further attention.

During the early 1990's in South Africa, there was a general decline in the workload handled by the construction sector. This was a result of the scale down of heavy infrastructure projects because of the government shifting focus to housing and other related projects, mainly as an effort to meet the needs of the previously disadvantaged communities. This trend was confirmed by [3] in the Western Cape Province where the value of tenders awarded dropped from R 518 million (1994) to R 120 million (1995) during the January to May period. In October 1995, three well-established civil engineering contractors in Western Cape went insolvent. In the survey and studies conducted, insolvency causal factors associated with insolvencies in general construction firms were identified [4-5]. These factors could be broadly classified into the categories of operational management, environmental, strategic, personal, cost overruns and various technological factors.

Economic factors are noteworthy, but are often perceived as being external to a firms' operation. Therefore firms may fail to recognize that their impact may lead to the termination of their operation. The construction industry has certain distinct characteristics that are susceptible to failure [6-9].

These are:

- Trading within a high uncertain environment e.g. uncertain ground conditions, unpredictable weather and labor availability

- $\quad$ The necessity to price a product before it is produced.

- The contractors have to make assumptions relating to: the likely duration of the project, adequacy conditions, uncertainty in bad weather and other contingencies [10].

- Competitive tendering as a means of pricing.

- $\quad$ The low fixed capital requirements for market entry, which result to an over capacitated market.

- Ease of entry into the civil construction industry given the lack in legislation, stating who may or may not build.

The most prominent cause of insolvency results from inadequate cash resources and the failure to convince creditors for cash availability [6, 7]. Even profitable firms could be forced into liquidation because the demand of payment of outstanding accounts could not be met at a critical time, considering the fact that the assets may be tied in long-term investments [7]. Furthermore, capital is often required to 
smoothen out the strains on the cash flows resulting from the occurrence of cost and uncertainty [6].

Escalating material prices coupled with high interest rates have forced the management of construction firms to focus on the control of cash flow as being critical to its survival [7]. Moreover the terms of payment stipulated in the contractual conditions and the escalation formulae (on contracts with escalation) require a great deal of expertise to apply, coupled with the task of ensuring promptness in the submission and payment of bills to ensure that the cash flow situation is controlled and improved (i.e. preventing the erosion of profit).

Capital is critical for a company to grow, given that at a certain point in time its fund requirement will exceed its fund generation. The financing of construction projects may be external and internal to an organization. Internal sources include the contractor's retained earnings from previous projects or investments and depreciation income obtained through depreciating assets, thus through their sale. External sources include bank loans and other financing mechanisms. These may be short or long term.

Good management implies an awareness of all factors making up a successful business, namely: good strategy, marketing, pricing and financial control. Financial mismanagement and management incompetence have been cited among the attributes that lead to the prominence of construction failures $[4,11]$. There need to be training amongst entrepreneurs on matters relating to financial management such as bookkeeping, tax planning, budgeting and cash flow management. Additionally, the lack of management information also contributes to the failure of businesses. The use of financial ratios and inter-firm comparisons have been cited as the most useful tools in providing management information which measure the overall effectiveness of any business [11]. Furthermore, management information permits managers to monitor, measure and evaluate the performance of the company at certain time intervals, with the attainment of an improvement of profitability in view

\section{SKILL SHORTAGES WITHIN THE CONSTRUCTION INDUSTRY}

According to the state of skills document compiled by the Department of Labour of the South African government [12], there was a growth in the size of the country's economically active population, from 10 million in 1997 to 15.9 million in 2002. This represents a growth rate of over $50 \%$. During the same period the number of employed people has increased, from 8.7 to 11.4 million. The most striking feature over this period has been the increase in the number of unemployed from 2.5 million in 1997 to 4.8 million in 2002 (see Figure 1).

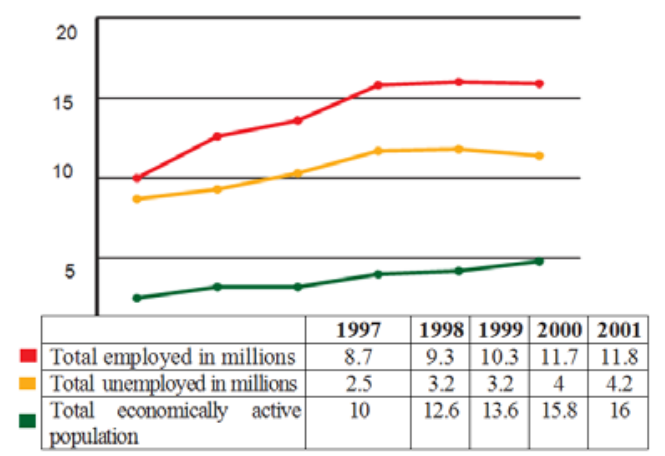

Fig. 1 Economically active, employed and unemployed in South Africa, $1997-2002$

Source: September 2002 Household Surveys and Labour Force Surveys, Statistics, South Africa.

The unemployed represent an important target group for the National Skills Development Strategy. It is vital that their skills be upgraded in order to facilitate their transition into active employment and life-long learning and to grow the skill pool from which employers can recruit.

Figures on the characteristics of the unemployed by educational level and population group are shown in Table I. The table illustrates the ongoing legacy of apartheid in that Africans are nearly seven times more likely to be unemployed than any other population group. Africans also constitute the largest number of those who have less than a Grade 12 or matric qualification, with African women exceeding men slightly in this category. But there are over 1 million people who are unemployed and who do have a Grade 12/matric or equivalent qualification. This represents an under-utilized human potential and is likely to be associated with high social costs that go with this exclusion.

TABLE I. EDUCATIONAL PROFILE OF THE UNEMPLOYED BY POPULATION GROUP AND GENDER (000s)

\begin{tabular}{|c|c|c|c|c|c|c|c|c|c|}
\hline & \multicolumn{3}{|c|}{ African } & \multicolumn{3}{c|}{ Other } & \multirow{2}{*}{ Total Male } & \multirow{2}{*}{ Total Female } \\
& Male & Female & Total & Male & Female & Total & & 2577 & 4836 \\
\hline Total* & 1965 & 2248 & 4213 & 194 & 329 & 623 & 2259 & 77 \\
\hline None & 80 & 88 & 168 & - & - & - & 83 & 94 & 77 \\
\hline$<$ Grade 12/matric & 1312 & 1417 & 2729 & 165 & 177 & 342 & 1490 & 1618 & 3108 \\
\hline Grade 12/matric or equivalent & 494 & 608 & 1102 & 93 & 104 & 197 & 591 & 715 & 1306 \\
\hline > Grade 12/matric & 70 & 122 & 192 & - & - & - & 81 & 136 & 217 \\
\hline
\end{tabular}

* Figures may not add up to total due to rounding and other statistical manipulations. Source: Labour Force Survey, Statistics, South Africa, September 2002. 
It is important to note that youth unemployment continues to be a striking feature of the South African labor market. Those in the 15 to 34 years age group make up the vast majority of the unemployed - the chances of being unemployed are three times higher for this age group, as reflected in Figure 2 . Moreover, most unemployed youths are African, with over 3 million in the 15 to 34 years age group compared to 411,000 for White, Indian and Coloured youth.

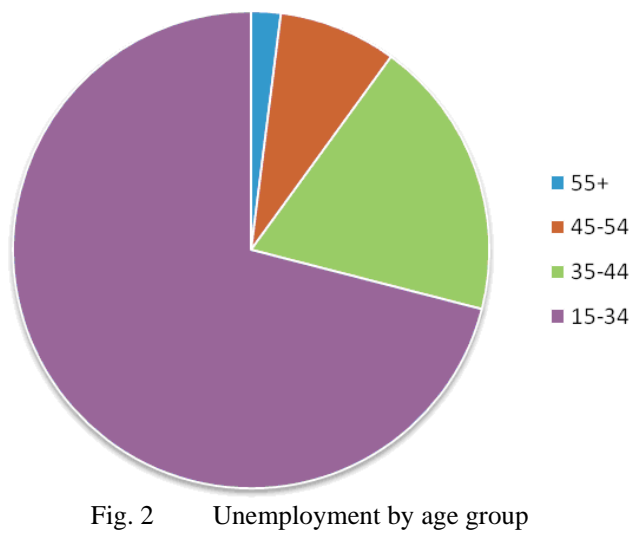

Source: Statistics SA, Labour Force Survey, Statistics, South Africa, September 2002.

The employed are an equally important target group for skills development, particularly through the work of the Sector Education and Training Authorities (SETAs). A significant labor market indicator for skills development is the current and changing skill level of those in employment. Of the 11.03 million workers employed in the South African economy:

- $\quad 6.7 \%$ had no educational qualifications
- $51.9 \%$ had an educational attainment below Grade 12/matric

- $\quad 25.1 \%$ had a Grade 12 / matric

- the remaining $15.2 \%$ had achieved a qualification level above Grade 12/matric.

If these figures are examined by gender, they reveal that qualification differences between men and women are small (see Table II):

- $\quad 7 \%$ of employed women have no qualifications, compared to a figure of $6 \%$ for men

- employed men with Grade 12 /matric make up 26\% of the total employed men, compared with $24 \%$ for women

- there are slightly more women in employment with a qualification higher than a Grade 12 /matric, a $17 \%$ share, compared to $14 \%$ for men.

When examined by population group, some important issues emerge from Table II:

- $\quad 9 \%$ of employed Africans have no qualification compared with $1 \%$ of Whites, Indians and Colored

- $\quad 29 \%$ of African workers have achieved a Grade 12/matric level qualification or higher compared with $64 \%$ for White, Indian and Colored workers.

These differences in the qualification level for Africans compared to other workers, pose an important challenge for linking of skills development to equity considerations in the workplace. It is encouraging to note, however, that the number of Africans with Grade 12/matric and higher qualifications has been growing between 1997 and 2002 (see Table III).

TABLE II. EDUCATIONAL QUALIFICATIONS OF THE WORKFORCE BY POPULATION GROUP AND GENDER (000S)

\begin{tabular}{|c|c|c|c|c|c|c|c|c|c|}
\hline & \multicolumn{3}{|c|}{ African } & \multicolumn{3}{|c|}{ Other } & \multirow{2}{*}{ Total Male } & \multirow{2}{*}{ Total Female } & \multirow{2}{*}{ Total } \\
\hline & Male & Female & Total & Male & Female & Total & & & \\
\hline Total* & 4028 & 3208 & 7236 & 2156 & 1632 & 3788 & 6184 & 4840 & 11024 \\
\hline None & 343 & 337 & 680 & 41 & 20 & 61 & 384 & 357 & 741 \\
\hline$<$ Grade 12/matric & 2521 & 1932 & 4453 & 745 & 528 & 1273 & 3266 & 2460 & 5726 \\
\hline Grade $12 /$ matric or equivalent & 785 & 512 & 1297 & 808 & 657 & 1465 & 1593 & 1169 & 2762 \\
\hline$>$ Grade $12 /$ matric & 326 & 404 & 730 & 539 & 412 & 951 & 865 & 816 & 1681 \\
\hline
\end{tabular}

TABLE III. CHANGES IN THE QUALIFICATION OF THE WORKFORCE BY POPULATION GROUP (000S)

\begin{tabular}{|l|c|c|c|c|c|c|c|c|}
\hline & \multicolumn{2}{|c|}{ None } & Less than Matric & \multicolumn{2}{c|}{ Matric } & \multicolumn{2}{c|}{ Post Matric } \\
\hline & African & Other & African & Other & African & Other & African & Other \\
\hline $\mathbf{1 9 9 7}$ & 642 & 66 & 3310 & 1195 & 880 & 1121 & 536 & 828 \\
\hline $\mathbf{1 9 9 8}$ & 762 & 66 & 3683 & 1127 & 887 & 1251 & 578 & 952 \\
\hline $\mathbf{1 9 9 9}$ & 667 & 75 & 4105 & 1299 & 1061 & 1274 & 667 & 1008 \\
\hline $\mathbf{2 0 0 0}$ & 803 & 55 & 5172 & 1288 & 1184 & 1057 & 729 & 1233 \\
\hline $\mathbf{2 0 0 1}$ & 801 & 52 & 5120 & 1240 & 1260 & 1240 & 763 & 2394 \\
\hline $\mathbf{2 0 0 2}$ & 680 & 61 & 4394 & 1194 & 1250 & 1368 & 837 & 2493 \\
\hline
\end{tabular}


Clearly, past historical imbalances are being addressed through education and training, although significantly more progress needs to be made before a parity of qualification levels is achieved between the different population groups in the workforce.

The South African government has put emphasis to transforming the sector to allow the participation of emerging and small contractors but this was not properly regulated as most of these contractors did not have the experience and skills to operate sustainable construction firms. Exacerbating this problem is the inadequate investment skills development across all levels in the sector, despite sufficient funding available from the Construction Education and Training Authority (CETA) and specific deficiencies include inadequate recognition of prior learning and work place training.

The Construction Industry Development Board (CIDB) was established in 2000 as a statutory body to provide leadership to stakeholders and to stimulate sustainable growth, reform and improvement of the construction sector for effective delivery and the industry's enhanced role in the country's economy. CIDB's regulations were implemented after 2003 and are continuously improving the sector's growth. The CIDB has realized that a vibrant and successful construction industry is only possible if those employed within it, have the required skills and competency to function effectively in their roles.

Investing in appropriate suitable training is vital and leads to improvements in productivity and, in the long term, to cost savings. Training should lead to qualifications recognized by the industry and the enablement of employees to demonstrate the level of attainment and competence reached.

The operation of the CIDB is the start of a long process. In order to realize tangible results in terms of performance improvement and prospects for the construction industry, several issues need attention. The CIDB should formulate long term plans for developing the industry [13]. There should be supported by comprehensive reviews of the state of the industry and its concerns and imperatives [14].

One of the most important resources is people. Skill shortage and development remains a pressing concern in South Africa and the construction sector is no exception [15]. With an increasing number of Small-to-Medium-Size-Enterprises (SMME) emerging in the construction sector, it becomes increasingly challenging for authorities to regulate the level of skills and training of the community's construction force [13].

Added to this is a lack of management level where a shortage of skilled project managers often has significant consequences for projects and businesses. While management skills are important areas of focus, the industry needs to invest in training from the bottom all the way to the top. Naturally, the quality of the company's employees is also reflected in the quality of the service they provide. This proves partially challenging for the construction sector where SMME make for a significant part, skill development is integral to the sustainable growth and where smaller companies developed within the industry lack the required resources to provide employees with the needed development and training opportunities [14]

\section{A. Discussion}

In order to obtain the necessary information on the subject, the following are considered:

- Findings from the "Construction Indaba 2011" held on the $1^{\text {st }}$ and $2^{\text {nd }}$ of June 2011 hosted by eThekwini Municipality's Business Support, Tourism and Markets in Durban, KwaZulu-Natal, South Africa. The Municipality invited construction contractors with a CIDB grading of level 2 or more. The Conference had speakers from different stakeholders sharing information and knowledge to empower contractors to become self sustainable entities whilst guiding them through the industry's most common challenges and factors that impact negatively on their business. Furthermore it furnished the opinion of the owners discussed at workshops in the conference of the causes which may have led to business failure or stifled growth.

- Conclusion and Recommendations based on the outcome of discussions with the civil engineering contractors.

\section{B. Findings}

The "Construction Indaba 2011" was attended by 276 Construction Company representatives from various parts of KwaZulu-Natal. The target group was contractors registered with CIDB level two grading or more. The level two grading contractors have the capacity to undertaken construction work over the value of R 200,000. The program had various speakers from government department, construction mentors and financial institutions.

Initially the study was going to be based on a questionnaire but after evaluating the target group, it was clear that the level of the questionnaire was going to be a challenge for most contractors since over $80 \%$ of them uses English as a second language. The interaction at the four workshops was conducted in isiZulu to the benefit of the contractors. Using isiZulu to conduct discussions made it comfortable for contractors to express their challenges with great emotions. The attendees were later divided into four groups according to the numbers they received during registration in order to discuss the challenges they face on their daily business activities.

The following were the main challenges highlighted:

- Human Resource development

- Lack of understanding tendering process

- Late payments affecting business cash flow

- Corruption in the industry

- $\quad$ Procurement policies not fully understood by Contractors

- Lack of knowledge to develop Business Plans for their businesses

- $\quad$ Securing of work

- Lack of understanding of the CIDB's role in the industry 
- Lack of operational and managerial skills amongst contractors

- Under pricing

- Lack of understanding of the general conditions of contracts

- Encourage established contractors to subcontract work to smaller contractors - partnering approach

- Improve transparency in the circulation of tender opportunities especially on invited tenders

- $\quad$ Establish a forum where they can share experiences.

It was noted during the group sessions that there was a negative feedback and a dissatisfaction regarding the way the industry treats them as stakeholders. The groups felt their concerns are currently inadequately addressed to assist them to grow as contractors.

The discussions revealed that the main concerns related to operational and financial management challenges although corruption was raised prominently as one of the main limiting factors for the sustainability of their businesses [15]. They felt that no matter how many resources are made available to assist them, it's pointless if work is only awarded to undeserving contractors.

\section{Success Story: Mentorship and Business Incubation- model}

A representative from the SEDA (Small Enterprise Development Agency) Construction Incubator shared some experience regarding one of their Contractor Development program at the conference. The program was established in 2006 as a government funded contractor development incubator under the banner of a ring fence incubator program called SEDA Technology Program. The core business is to develop emerging contractors through the infusion of both technical and business administration skills that are aligned with the introduction of technology in order to enhance the efficiency and efficient management of their businesses. The incubator provides support to selected participants for a period of 3 years by which time each the emerging contractor should have advanced by at least one financial level above its entry point on the CIDB register and should be capable of operating unassisted in the open market.

In the development of the program, the ethos of the mission and vision is carried forward by means of an appropriate approach towards mentorship. The success and failure of the organization is determined by the quality of its product and the directing market forces that it influences. There is constant interaction with incubates through workshops as guidance to those who have limited knowledge of the workings of the construction industry. Incubates are taken through from tender to completion stages. To this end the program has supported about 63 contractors with a success rate of $95 \%$ of contractors who remained in the program for the full duration of three years.

\section{A Typical Participants in the SEDA Contractor Program}

Velile Business Enterprise is a general building construction company owned and managed by Florence Malinga. She joined the program in February 2007 as a grade 3 GB. Since then Velile has been showing growth as contractor and as business.

Before getting involved in construction projects, Florence Malinga was a clothing designer for many years. When she started operating as a Sole Proprietor in 2000 her first project (with Engineering Municipality) had a budget in the region of R 2000 to R 3000, and she grew to a point where she concentrated more into plumbing contracts with better projects amounting to R 127,000 by 2002. Velile Business Enterprise was then registered as a CC. It worked with various government departments like Public Works and Housing. Velile has been renovating municipality hostels in Durban, South Africa for two and a half years. Most of these hostels were renovated and changed to flats for residential dwelling of the community.

During 2007, Velile renovated more than 40 flats and even more during 2008 and this was due to the high level of performance and the displayed quality. This led to Velile being awarded more work every year which led to its growth as a business and also regarding its CIDB grading. Velile Business Enterprise reached 6 grades of growth and acquired a project exceeding R 20,000,000

\section{E. Conclusion}

The new breed of novice contractors is flooding the market with the hope of success. However, the South African culture and its linguistic diversity must be taken into consideration in any research study, in particular when it involves the construction industry, as it posses as one of the ethnic work forces in the country. The lack of construction education appears to be one of the major hurdles for small enterprises. Many of the new entrants into the construction sector, have little construction related education and/or poor English skills but these individual are still allowed to set up construction companies.

At the "Construction Indaba 2011" all participants expressed the desire to learn and retrain. It appeared that current education strategies are not designed to accommodate such people. New strategies need to be applied and different learning styles need to be properly managed by educators and researchers with tangible knowledge of the deficiencies and the needs of the industry.

The outcry from the contractors indicates that the influence of the government is substantial in assisting the construction industry to develop. The government's role as a major client for engineering contractors combined with its role in creating, maintaining and initializing a conducive environment whether this is defined as business education or in other terms.

Industry stakeholders need to develop well researched development programs in conjunction with academia. The attitude towards each other needs to change to achieve a 
common goal: the design of contractor development programs which relate to the needs of the construction industry. Research needs construction industry if construction programs are to survive in tertiary institutions [16].

\section{F. Recommendations}

Given the identification of education and training, skills development and human resource development in general, a further possible parameter in the form of development should be included. The industry should also endeavor to:

- Realize $100 \%$ educational mentoring and training.

- Increase the amount of research and development especially on oral training programs to individuals with less academic background.

- Engender a partnering approach to improve collaboration among stakeholder within the construction sector

- Influence government's policies relating to the construction industry.

\section{REFERENCES}

[1] Department of Public Works, "Creating an enabling environment for reconstruction, growth and development in the construction industry", White Paper for Public Works, Pretoria, South Africa, 1999

[2] S. Dlugwana, X. Nxumalo, S. Van Huyssteen, P. D. Rwelamila,C. Noyana, "Development and implementation of the South African Construction Excellence Model (SACEM)”, First International Conference on Construction in the 21st Century, Florida, USA, 2002

[3] E. Symon, "Crisis in the Cape”, The Civil Engineering Contractor, Vol. 30, No. 2, pp. 7-11, 1995

[4] A. Henry, "An investigation into factors associated with insolvencies in the building firms”, B.Sc. Dissertation, University of Cape Town, 1994.

[5] P. D. Rwelamila, L. Lobelo, "Factors associated with insolvencies amongst civil engineering contractors in South Africa”, RICS Construction and Building Research Conference (COBRA '97), pp. 282298, Portsmouth, United Kingdom, 1997

[6] H. Ren, "Risk management in construction cost and inflation”, D.Sc. Thesis, University of Reading, 1992

[7] A. R. Jach, "Cash flow forecasting for the contractor", B.Sc. Dissertation, University of Cape Town, 1985

[8] R. Kangari, "Business failure in the construction industry", Journal of Construction Engineering and Management, No.114, No. 2, pp. 172-190, 1988

[9] R. Davis, Construction insolvency, Sweet \& Maxwell Ltd, United Kingdom, 2011

[10] A. E. Olusegun, A. O. Michael, "Abandonment of construction projects in nigeria: causes and effects”, Journal of Emerging Trends in Economics and Management Sciences, Vol. 2, No. 2, pp. 142-145, 2011.

[11] J. J. Potgieter, A. B. Frank, Ratio analysis and inter-firm comparisons as a means of providing management information in the small business sector, University of Zululand, South Africa, 1990

[12] Department of Labour, State of Skills in South Africa for Formulation of the National Skills Development Strategy, Government, Pretoria, 2003

[13] F. Calldo, "Skills shortage in South Africa: the facts and what is being done”, Solidarity Research Department, 2007

[14] W. Franck, “Addressing Skills Shortage in the Built Environment”, Biz Community News, Johannesburg, South Africa, March 2013.

[15] W. Shakantu, C. Chiocha, "Corruption in the construction industry: the case of Malawi”, COBRA 2009: Cape Town, South Africa, 10-11 September 2009
[16] Construction Industry Development Board (CIDB), "Baseline study of Provincial Contractor Development Programs: Review of the Contractor Development Programs towards an NCDP monitoring and evaluation system". [Online], Available from www.cidb.org.za (accessed: 07 April 2012)

\section{AUTHORS PROFILE}

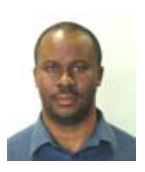

Bonga Ntuli holds A Bachelor's Degree in Technology Civil Engineering and he is currently studying towards his Masters Degree in Technology (Civil Engineering) at the Durban University of Technology. He is registered with the Engineering Council of South Africa as a Professional Engineering Technologist (PrTech Eng) and is a member of the South African Institute of Civil Engineers (MSAICE). He has experience in sanitation and water engineering projects in all phases of water infrastructure ranging from feasibility studies including financial analysis, preliminary and detail designing. He has been involved in contract management of Public Works Community based projects and projects mentoring emerging contractors. He is currently employed at Royal HaskoningDHV (SA) as a Director of Advisory Group for the Water Business Unit in KwaZulu-Natal, South Africa and is responsible for both commercial and technical performance of the water business Unit.

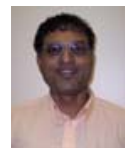

Prof Dhiren Allopi is the Associate Professor/Director in the Department of Civil Engineering and Surveying at the Durban University of Technology. He has five qualifications from four different tertiary institutions including a Doctorate Degree in Civil Engineering. Prof Allopi has over 33 years of combined industrial and academic experience mainly in the field of geotechnical, traffic and transportation engineering. He has over 70 conference proceedings and journal papers to his credit. $\mathrm{He}$ is professionally registered with the Engineering Council of South Africa and is a fellow member of the South African Institute of Civil Engineering. He has lectured to diploma and degree students and is currently supervising ten postgraduate students mainly in the field of traffic and transportation engineering. 